\title{
Optimization of Finasteride Nano-Emulsion Preparation Using Chemometric Approach
}

\author{
Soheila Honary ${ }^{1 *}$, Pouneh Ebrahimi ${ }^{2}$ and Mahshid Nikbakht ${ }^{1}$ \\ ${ }^{1}$ Mazandaran University of Medical Sciences, School of Pharmacy, Sari, ${ }^{2}$ Department of Chemistry, Gonbad Kavous University, \\ PO Box 163, Gonbad, Iran
}

*For correspondence: Email: Shonary@yahoo.com; honary@ualberta.ca

\begin{abstract}
Purpose: To study the effect of some factors on the size of finasteride nano-emulsion by chemometric approach which could predict the size of nano-emulsion droplets under different conditions.

Methods: Nano-emulsions were prepared using spontaneous emulsification method which occurs when organic and aqueous phases are mixed. The organic phase was a homogeneous solution of oil (finasteride as a lipophilic drug) and water-miscible solvent with or without lipophilic surfactant (Span ${ }^{\circledR}$ 80 ), while the aqueous phase consisted of water with or without hydrophilic surfactant (Tween ${ }^{\circledR} 80$ ). Chemometric approach was applied for optimizing the size of the nano-emulsion droplets. For this purpose, the effect of three experimental parameters on size was investigated by multivariant analysis. The experiments were performed according to Box-Behnken experimental design. The factors considered were sonication time $(0-5 \mathrm{~min})$, and contents of Span-80 (0 - $0.16 \%)$ and Tween-80 (0 $0.26 \%$ ).

Results: The regression model obtained was characterized by both descriptive and predictive ability. The method was optimized with respect to average diameter as a response, based on a defined equation

Conclusion: The Box-Behnken experimental design is a suitable tool for optimizing and testing the robustness of the method for preparing finasteride nano-emulsion.
\end{abstract}

Keywords: Box-Behnken experimental design, Optimization, Nanoemulsion, Finasteride.

Tropical Journal of Pharmaceutical Research is indexed by Science Citation Index (SciSearch), Scopus, International Pharmaceutical Abstract, Chemical Abstracts, Embase, Index Copernicus, EBSCO, African Index Medicus, JournalSeek, Journal Citation Reports/Science Edition, Directory of Open Access Journals (DOAJ), African Journal Online, Bioline International, Open-J-Gate and Pharmacy Abstracts

\section{INTRODUCTION}

Drug absorption and efficacy are severely affected by poor solubility in a vehicle, and hence design of effective formulations for poorly soluble drugs has been a major challenge for many years. Solubility and bioavailability of lipophilic drugs will be enhanced by using nanoemulsion drug delivery systems. Nanodroplets are able to increase the proportion of interfacial area to the total volume of droplets and it would influence the transport properties of the drug [1].
Most of the time, nanoemulsions are oil-inwater dispersions, having droplets with 100 - $600 \mathrm{~nm}$ diameter [2]. They are kinetically and physically stable for long time without apparent flocculation or coalescence [3] and are also stable against dilution and even temperature [4]. Nanoemulsions present several advantages such as the low surfactant concentration required $(3-10$ $\%)$; uniform deposition and good absorption through skin because of its small droplet size, and good penetration of active ingredients into stratum corneum and even hair follicle [5]. 
There are two major techniques of preparation of nanoemulsions: 1) high energy method (e.g., microfluidization and high pressure homogenization), and 2) low energy method (e.g., phase inversion temperature method and spontaneous emulsification) [6]. Nanoemulsion preparation using spontaneous emulsification method consists of simply mixing oil (plus lipophilic surfactant) and water (plus hydrophilic surfactant) in the right proportion at room temperature $[7,8]$. According to this method, nanoemulsions form with rapid and specific spread of organic solvent from oily phase to aqueous. This method has several advantages such as lack of residual organic solvent, low cost, high capacity for loading both lipophil and hydrophile drugs and long shelf life $[9,10]$.

Chemometrics methods are a new experimental design that cause less laboratory work, less experimental trials and less material consumption. Box Behnken Design (BBD), is one of these methods which shows good ability for optimization of the pharmaceutical formulation process. In this method, unlike the conventional methods, all factors change simultaneously and this leads to evaluation of each factor in different levels of other factors and their effect on each other [11,12].

Finasteride is a competitive and specific steroidal inhibitor of type II 5 a-reductase, that interact with androgenic based hair loss at oral doses of $1 \mathrm{mg} /$ day. In oral use, adverse reactions occurring in $3 \%$ or more of patients include abnormal ejaculation, asthenia, decreased libido, decreased volume of ejaculate, dizziness and postural hypotension [13-15].

In this study, experiments used for modeling droplet size were performed on three levels of three factors, using Box-behenken experimental design to find out the effect of each factor and their interactions on the particle size of nanoemultion as well.

\section{EXPERIMENTAL}

\section{Chemicals}

Finasteride (FA) powder was a gift from Soha Helal (Iran), Surfactants $\left(\right.$ Span $^{\circledR} 80$ and $\operatorname{Tween}^{\circledR} 80$ ), absolute ethanol and other chemical reagents were purchased from Merck (Germany).

\section{Preparation of nanoemulsion}

A homogenous organic solution, composed of oil phase (finasteride and lipophilic surfactant i.e., Span $\left.{ }^{8} 80\right)$ in water-miscible solvent $(40 \mathrm{ml}$ absolute ethanol), was prepared while the homogenous aqueous phase consisted of double de-mineralized water $(80 \mathrm{ml})$, and hydrophilic surfactant (Tween 80). The organic phase was injected into the aqueous phase under magnetic stirring (Heidolph MR3001, 750 $\mathrm{rpm}$ ) for $30 \mathrm{~min}$. O/W emulsion was formed spontaneously by diffusion of the organic solvent into external aqueous phase, leading to the formation of submicron droplets. Magnetic stirring was continued for $30 \mathrm{~min}$ to reach equilibrium in the system. The mixture was sonicated for various duration ranging from $0-5$ min with Bandelin sonicator to produce a homogenized system. The water-miscible phase added $(20 \mathrm{ml})$ was removed by evaporation (under reduced pressure at $45^{\circ}$ $\mathrm{C}$ and $90 \mathrm{rpm}$ ). The solution was sonicated again for 1 min with Bandelin sonicator.

\section{Determination of droplet size}

Droplet size were determined with a particle analyzer (Zetasizer 3600 ) at $25^{\circ} \mathrm{C}$ at a scattering angle of $90^{\circ}$ (Malvern Instruments, UK).

\section{Experimental design}

The experiment trials were carried out using three factors that were considered most effective on response (particle size). The three factors were sonication time before evaporation (st), Span-80 concentration (sc) and Tween-80 concentration (tc), as shown in Table 1. The selected levels of variables were based on initial pilot studies.

Table 1: The three studied factors and the corresponding three level settings

\begin{tabular}{cccc}
\hline Level & st & tc & sc \\
\hline-1 & 0 & 0 & 0 \\
0 & 2.5 & 0.163 & 0.1 \\
+1 & 5 & 0.325 & 0.2 \\
\hline
\end{tabular}

Statistical analyses of the multiple regression were also performed on range-scaled factor values of $[-1,+1]$ using backward method with the aid of SPSS software. 


\section{RESULTS}

All experiments and measurements were in duplicate. The experimental values of droplet size for all the experiments are reported in Table 2.

Droplet size values for the complete set of 15 experiments were fitted to the polynomial model. Least square method was used by a variable selection algorithm (backward search) in SPSS software to find a model that describes efficiently the dependence of droplet size on the experimental parameters. The model obtained and its statistics are reported in Table 3. Criteria for the evaluation of the descriptive capability of the model were Fisher-ratio value $(F)$, squared correlation coefficient $\left(R^{2}\right)$, and standard error of the estimate (SE). Different polynomials with all possible combinations of the factors were generated. It was found that the simplest polynomial that successfully described the system under study was third order equation.

To find the optimum condition in the preparation of FA nanoemulsions, a grid search was performed in Excel software. In this software, the droplet size was predicted from the model within the feasible factor space. Prediction was performed for all conditions; 398 different experimental conditions were predicted using the model obtained.

Table 2: Experimental conditions for Box-Behenken design and mean response for droplet size

\begin{tabular}{ccccc}
\hline Trial & st & tc & sc & $\begin{array}{c}\text { Mean } \\
\text { diameter } \\
\text { (nm) }\end{array}$ \\
\hline 1 & 1 & 1 & 0 & 300 \\
2 & 1 & -1 & 0 & 182.3 \\
3 & -1 & 1 & 0 & 217 \\
4 & -1 & -1 & 0 & 131.3 \\
5 & 1 & 0 & 1 & 177.9 \\
6 & 1 & 0 & -1 & 1526 \\
7 & -1 & 0 & 1 & 130.8 \\
8 & -1 & 0 & -1 & 1602 \\
9 & 0 & 1 & 1 & 226.3 \\
10 & 0 & 1 & -1 & 1967 \\
11 & 0 & -1 & 1 & 159.5 \\
12 & 0 & -1 & -1 & 1141 \\
13 & 0 & 0 & 0 & 150.67 \\
14 & 0 & 0 & 0 & 145.3 \\
15 & 0 & 0 & 0 & 138.1 \\
\hline
\end{tabular}

\section{DISCUSSION}

The low value of SE and the high value of $R^{2}$ and $F$ statistics indicate that the model is successful in calculating droplet size. The model obtained indicates that two-factor interactions with first orders have significant effect on the droplet size value. This means that the respective response hypersurfaces in the multidimensional factor space are curved in the sphere of the experimental design. It is also noteworthy that the terms - st, sc and tc×sc - showed negative contributions to the dependent variable, while the term, tc, showed positive contribution. The most significant mean effect belong to sc (mean effect $=-0.809$ ) which shows the droplet size dramatically affected by Span concentration. Determination of the importance of the factors in the model by the standardized coefficient demonstrates that the interaction between st and sc has a positive contribution on the droplet size. Therefore, the existence of interaction terms between the main factors under the conditions of our experiments emphasizes the necessity to carry out active multifactor experiments for determining the optimal condition of finasteride nano-emulsions.

Table 3: Intercept, coefficients and mean effects for the predictive model obtained for three factors

\begin{tabular}{lll}
\hline Mean effect & Coefficient & Variable \\
\hline- & 129.547 & intercept \\
-0.05 & -46.942 & $\mathrm{st}$ \\
0.1 & 93.094 & $\mathrm{tc}$ \\
-0.809 & -755.836 & $\mathrm{sc}$ \\
0.109 & 144.327 & $\mathrm{st} \times \mathrm{sc}$ \\
-0.102 & -134.500 & $\mathrm{tc} \times \mathrm{sc}$ \\
0.075 & 101.968 & $\mathrm{tc}^{2}$ \\
0.546 & 747.383 & $\mathrm{sc}^{2}$ \\
\hline
\end{tabular}

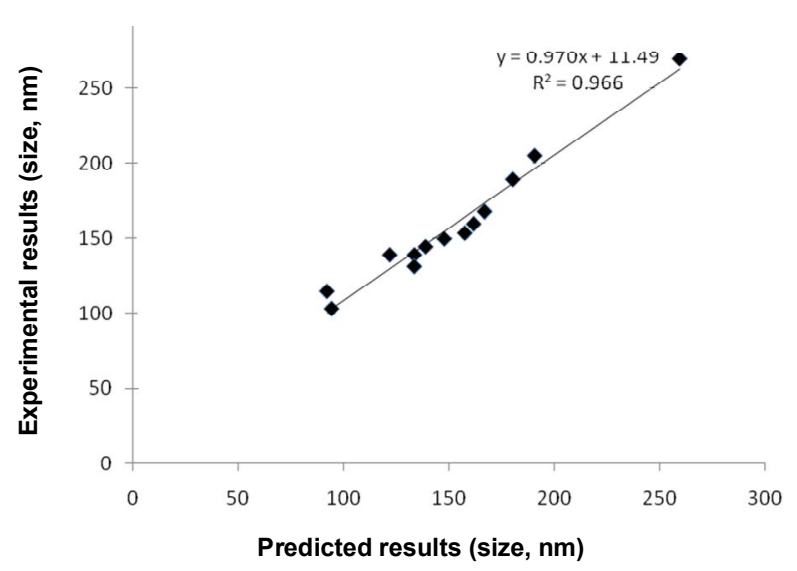

Fig 1: Predicted vs experimental finasteride nanodroplet size for 15 experimental conditions not entered in the modeling.

The efficiency of prediction of the polynomial model was confirmed by performing the experiment under some of the proper conditions with the lowest droplet size (Figure 1). The results also show a good agreement between predicted and experimental droplet size under 
the selected conditions. Therefore, the suitability of the model developed for interpreting the experimental space and indicating the optimum experimental condition was confirmed.

Also, to assess the suitability of obtained MLR model, the residuals were analyzed statistically. Figure 2 shows a good agreement between predicted and experimental results for 22 experimental conditions. From the plot of Figures 1 and 2, it can be observed that the fitting of this model and the model prediction ability is satisfactory."

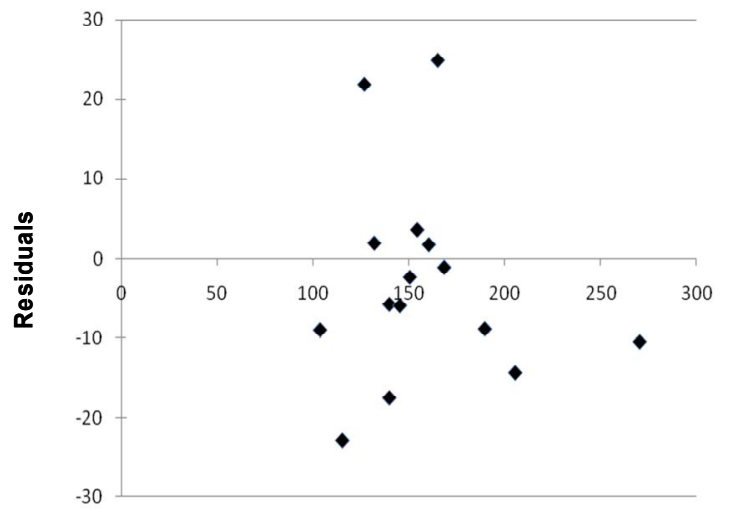

Experimental results (size, $\mathrm{nm}$ )

Fig 2: The residual plot for the predicted size of finasteride nanodroplets according to the regression model reported in Table 3

Spontaneous nano-emulsification is a process that is based on diffusion of a solute into the phase in which it has greater solubility. In this process, droplets are created as a result of rapid diffusion of absolute ethanol as a water-soluble solvent, solublized first in the organic phase, moving towards the aqueous one when the two phases are mixed. Thus, its behaviors can potentially be predicted by diffusion pathway. The results show that surfactants (especially Span-80) play a key role in nanoemulsion physical stability. Without surfactants, the nanoemulsion generated showed poor stability with bigger droplets owing to apparent flocculation or coalescence.

\section{CONCLUSION}

A chemometric approach allowed the determination of the optimum conditions for the preparation of finasteride nanoemulsions with a limited number of experiments. The results showed that droplet size regularly changes as a function of Span-80 and Tween-80 concentrations and sonication time. Furthermore, the Box-behenken design permits the determination of a regression model, which describes the dependence of droplet size on the experimental parameters for the preparation of finasteride nanoemulsions. The results obtained also indicate that the emulsification-evaporation technique is an efficient technique to stabilize the droplet size of the nanoemulsions.

\section{REFERENCES}

1. Lawrence MJ, Rees GD. Microemulsion-based media as novel drug delivery systems. Adv. Drug Deliver. Rev. 2000; 45: 89-121.

2. Ugelstadt J, El-Aassar MS, Vanderhoff JW. Emulsion polymerization - initiation of polymerization in monomer droplets. J. Polym. Sci. 1973; 11: 503-513.

3. Tadros $F$, Vandamme $A$, Levecke $B$, Booten $K$, Stevens CV. Stabilization of emulsions using polymeric surfactants based on inulin. Adv. Colloid. Interf. Sci. 2004; 108-109: 207-226.

4. Anton $N$, Benoit JP, Saulnier $P$. Design and production of nanoparticles formulated from nano-emulsion templates - $A$ review, J. Control. Release 2008; 128: 185-199.

5. Bouchemal K, Briançon S, Perrier E, Fessi H. Nanoemulsion formulation using spontaneous emulsification: solvent, oil and surfactant optimization, Int. J. Pharmaceut. 2004; 280: 241-251.

6. Sonneville-Aubrun $O$, Simonnet JT, L'Alloret $F$. Nanoemulsions: a new vehicle for skin care products. Adv. Colloid Interface Sci. 2004; 108-109: 145-149.

7. Kelmann RG, Kuminek G, Teixeria HF, Koester LS. Carbamazepine parenteral nanoemulsions prepared by spontaneous emulsification process. Int. J. Pharmaceut. 2007; 342: 231239.

8. Ganachaud F, Katz JL. Nanoparticles and nanocapsules created using the ouzo effect: spontaneous emulsification as an alternaive to ultrasonic and high-shear devices. Chem. Phys. Chem. 2005; 6: 209-216.

9. Azeem A, Ahmad FJ, Khar RK, Talegaonkar S. Nanocarrier for the Transdermal Delivery of an Antiparkinsonian Drug, AAPS Pharm. Sci. Tech. 2009; 10: 1093-1103.

10. Heuschkel S, Goebel A, Neubert R. Microemulsions modern colloidal carrier for dermal and transdermal drug delivery. J. Pharm. Sci., 2008; 97: 603-631.

11. Ferreira $S$, Bruns $R$, Ferreira $H$, Matos $G$, David, J, Brandao G, Silva $E$, Portugal $L$, Reis $P$, Souza A, Santos W. Box-Behnken design: An alternative for the optimization of analytical methods, Anal. Chim. Acta. 2007; 597: 179186.

12. Torbjorn Lundstedt, Seiferta E, Abramob L, Thelinc $B$, Nyströma A, Pettersena J, Bergman $R$. experimental design and optimization. Chemometr. Intell. Lab. 1998; 42: 3-40.

13. Bhasin S, Storer TW, Berman N, Callegari C, Clevenger $B$, Phillips J, Bunnell $T$, Tricker $R$, Shirazi A, Casaburi $R$. The effects of supraphysiologic doses of testosterone on muscle size and strength in normal men. N. Engl. J. Med. 1996; 335: 1-7.

14. Olsen EA, Messenger A, Shapiro J, Bergfeld $W$, Hordinsky M, Roberts J, Stough D, Washenik K, Whiting $D$. Evaluation and treatment of male and female Pattern hair loss, J. Am. Acad. Dermatol. 2005; 52: 301-311.

15. Rogers NE, Avram MR. Medical treatments for male and female pattern hair loss. J. Am. Acad. Dermatol. 2008; 59: 547-66. 
Honary et al 